\title{
Práticas inclusivas de ciências humanas no ensino fundamental: saberes construídos
}

\section{Inclusive practices of human sciences in elementary school: built knowledge}

\author{
Mara Aparecida de Miranda Batista Dias ${ }^{1}$ \\ Edgar Zanini Timm² \\ Norberto da Cunha Garin ${ }^{3}$
}

\section{RESUMO}

Objetiva-se compreender saberes e práticas de professores da área das ciências humanas que em sua formação docente houve ausência da temática da inclusão e na contemporaneidade atuam na Rede Estadual de Educação de Uruguaiana/RS, no que se refere a contribuiçãopara a inclusão escolar. A partir dos resultados da pesquisa foi elaborada a proposta a qual se constituiu num produto: Guia de Boas Práticas Docentes sobre a inclusão de alunos com deficiência. Tratando de um estudo qualitativo, foram realizadas entrevistas semiestruturadas em cinco escolas de ensino fundamental, com cinco professores, sendo um de cada instituição escolar.

\section{PALAVRAS-CHAVE}

Educação. Ciências humanas. Professor. Inclusão. Práticas inclusivas.

\footnotetext{
${ }^{1}$ Professora, Mestra pelo Programa de Pós-Graduação Stricto Sensu em Reabilitação e Inclusão do Centro Universitário Metodista - IPA. Tem experiência pedagógica na área das Ciências Humanas.email: marademiranda@bol.com.br ${ }^{2}$ Graduado em Educação Física pela UFRGS; em Filosofia, mestre em Educação e doutorado em Educação (PUCRS). Docente do Centro Universitário Metodista - IPA.

${ }^{3}$ Graduado em Licenciatura em Filosofia (UPF), em Teológico pelo Instituto João Wesley, graduado em Bacharel em Teologia Complementação pelo Instituto Metodista de Ensino Superior, mestrado em Teologia pela Faculdade EST e doutorado em Teologia pela Faculdade EST. Tem experiência na área de Filosofia, com ênfase em Introdução À Filosofia, atuando principalmente nos seguintes temas: espiritualidade, educação, inclusão, teologia e bíblia.
} 


\section{ABSTRACT}

The objective is to understand the knowledge and practices of teachers in the human sciences area that in their teacher education lacked the theme of inclusion and currently work in the State Educational System of Uruguaiana/RS, regarding the contribution to school inclusion. From the results of the research, a proposal was elaborated and it was constituted in a product: Guide of Good Teaching Practices about the inclusion of students with disabilities. In a qualitative study, semi-structured interviews were conducted in five elementary schools, with five teachers, one from each school institution.

\section{KEYWORDS}

Education. Human Sciences. Teacher. Inclusion. Inclusive practices. 


\section{INTRODUÇÃo}

No Brasil, a inclusão de alunos com deficiência na rede regular de ensino ainda está sendo implementada, apesar de constar na legislação brasileira desde a redemocratização do Brasil, quando as leis foram alteradas, e outorgada a nova Constituição Federal de 1988, onde podemos observar que os objetivos fundamentais partem do princípio da inclusão, em seu Art. $3^{\circ}$ podemos destacar o item III que aponta a redução das desigualdades sociais e o item $V$ que destaca a promoção do bem de todos, sem preconceitos de origem, raça, sexo, cor, idade e quaisquer outras formas de discriminação. (BRASIL,1988). Este avanço na legislação garantiu o direito das pessoas com deficiência, tratando-as com igualdade.

Nessa perspectiva, após muitos anos, várias outras leis, decretos e emendas foram criadas para favorecer o processo de inclusão na rede de ensino. 0 processo de educação inclusiva vigente é complexo e caminha lentamente, pois incluir o aluno com deficiência vai muito além de inseri-lo na sala de aula regular, várias diretrizes precisam ser encaminhadas para se obter um resultado satisfatório: como acessibilidade, formação de professores e funcionários, disponibilidade de recursos pedagógicos, mudança da mentalidade cultural da comunidade escolar e da sociedade.

Este estudo foi inspirado a partir de vários questionamentos decorrentes de leituras e vivências como docente nos ensinos fundamental e médio da educação básica no estado do Rio Grande do Sul, Brasil, aliado a constatação de uma lacuna na composição curricular na formação, nos cursos de Estudos Sociais e História, com relação à preparação do professor para atender a um novo formato da educação vigente na legislação: a inclusão escolar.

Frente a esses aspectos e baseado nos objetivos do Programa de Pós-Graduação em Reabilitação e Inclusão do Centro Universitário Metodista - IPA, no Curso de Mestrado Profissional em Reabilitação e Inclusão, na linha de pesquisa Dimensões Educacionais na Inclusão, foram investigados nesta pesquisa saberes advindos da experiência prática de professores da área de ciências humanas, do ensino fundamental, construídos a partir do seu trabalho em escolas públicas estaduais, como produtos da vivência-experiência.

\section{METODOLOGIA}

No primeiro momento, o projeto de pesquisa foi submetido ao Comitê de Ética em Pesquisa (CEP/IPA) por tratar de coleta de dados em pesquisas qualitativas que envolvem seres humanos para a apreciação. Após a aprovação do CEP, mediante o parecer número 1.340 .233 , de 26 de novembro de 2015 ,foi realizado contato com a $10^{\text {a }}$ Coordenadoria de Educação para identificar o número de alunos com deficiência certificados por laudo médico matriculados na rede estadual da cidade de Uruguaiana/RS, no ensino fundamental.

Após a identificação das escolas, foi realizado o contato com as direções e os professores da área das Ciências Humanas,verificado suas disponibilidades e a certificação dos currículos da graduação, necessários para a realização da pesquisa. Desse modo se obtevea autorização mediante a assinatura do Termo de Autorização Institucional (TAI).

De possedesta autorização, cinco professores, sendo um de cada escola, foram convidados a ler e assinar o Termo de Consentimento Livre e Esclarecido (TCLE) no qual constavam os objetivos e procedimentos metodológicos bem como riscos e benefícios para os mesmos durante a realização da pesquisa.

Na sequência, os participantes foram convidados para agendamento do dia e da hora para realização da entrevista. Assim, os dados foram coletados por meio de uma entrevista semiestruturada individual com cada um dos participantes e de um diário de campo contemplando as duas dimensões de um diário conforme referido.

A pesquisa utilizou análise qualitativa dos dados obtidos. Para sua operacionalização, teve por base a Análise de Conteúdo, de Bardin (2011).

As entrevistas analisadas individualmente e no seu conjunto, no cruzamento com o referencial teórico, possibilitaram as construções de compreensão necessárias na perspectiva dos objetivos traçados para a pesquisa. 


\section{Resultados e discussões}

A partir das respostas dos participantes, dos objetivos da pesquisa e da Análise de Conteúdo, apresento os resultados alcançados organizados em seis momentos: 1) A inclusão e sua abordagem na formação acadêmica na graduação na área das ciências humanas; 2) A prática profissional frente à realidade da inclusão escolar; 3) Dificuldades encontradas pelos professores face ao processo de inclusão de alunos com deficiência; 4) Práticas inclusivas desenvolvidas pelos docentes; 5) Contribuição docente para a prática da inclusão; 6) Guia de Boas Práticas.

\section{A INCLUSÃO E SUA ABORDAGEM NA FORMAÇÃO ACADÊMICA NA GRADUAÇÃO NA ÁREA DAS CIÊNCIAS HUMANAS}

Na análise das respostas sobre como foi tratada a inclusão nos estudos da graduação, constatou-se que todos os entrevistados afirmaram que o tema não foi abordado de modo específico em seus estudos universitários.

O conjunto das respostas permitiu conhecer a realidade sobre a formação dos docentes pesquisados, levando à constatação de que a universidade cursada pelos entrevistados não estava cumprindo com a exigência legal vigente na época.

Conforme a legislação nacional, o tema deveria constar no currículo dos cursos de licenciaturas no período de formação dos professores entrevistados, (1988 a 2004). A exigência legal foi determinada a partir da Portaria 1793/1994, do Ministério da Educação e do Desporto, a qual considerou necessária a complementação dos currículos de formação de docentes e outros profissionais que atuam com portadores de necessidades especiais:

Art.1ํ. Recomendar a inclusão da disciplina "ASPECTOS ÉTICO-POLITICOEDUCACIONAIS DA NORMALIZAÇÃO E INTEGRAÇÃO DA PESSOA PORTADORA DE NECESSIDADES ESPECIAIS", prioritariamente, nos cursos de Pedagogia, Psicologia e em todas as Licenciaturas. (BRASIL, 1994, p irregular).
Nesta conjuntura constata-se que as bases legais afirmam e ressaltam a importância da preparação de professores para o atendimento do aluno com deficiência na rede regular de ensino, contradizendo a vivência e formação dos professores entrevistados.

Diante do exposto, avalio que os professores entrevistados atuantes na rede regular de ensino, não foram preparados para atender os alunos com deficiência, pois conforme seus depoimentos os currículos da universidade foram inadequados para a contemplação de uma educação inclusiva de fato.

\section{A PRÁTICA PROFISSIONAL FRENTE À REALIDADE DA INCLUSÃO ESCOLAR}

No estudo das respostas sobre como foi a atitude dos professores, na prática profissional, frente à realidade da inclusão escolar, evidenciei dois níveis de entendimento: a) sentimentos dos professores; b) desafio à busca de informações e aprendizado.

\section{Sentimento dos professores}

Dos cinco professores entrevistados, quatro deles afirmaram que, ao iniciarem as suas atividades no Magistério, quando se depararam com a realidade da inclusão escolar, na sala regular de ensino, sentiram-se receosos, desanimados e apavorados com a situação, afinal, não se sentiam preparados para a prática inclusiva

Conforme revelam esses resultados, para boa parte dos professores entrevistados, os sentimentos iniciais foram de desânimo, e medo ao se depararem com a realidade escolar inclusiva.

A averiguação feita nesta pesquisa comprova o despreparo dos professores entrevistados para suas práticas profissionais na educação inclusiva.

\section{Desafio à busca de informações e aprendizado}

A busca por conhecimentos pelos profissionais da educação é uma constante. Analisando as respostas, constatei que os professores entrevistados 
usaram de seus medos para construir um aprendizado diante da inclusão. Acredito que a valorização do seu compromisso com os alunos foi um fator positivo para enfrentarem a situação de despreparo.

Dos cinco entrevistados, dois professores relataram que se valeram do despreparo para buscar conhecimentos na perspectiva da educação inclusiva.

A partir da assimilação dos fatos, todos os entrevistados afirmaram que foram se adequando a realidade da inclusão na sala de aula e aprendendo com a situação.

Percebe-se, a partir do estudo, que os docentes entrevistados tiveram um novo olhar para os alunos inclusos, realizando as alterações necessárias para o acolhimento destas crianças.

No contexto inclusivo, a prática pedagógica adequada face ao processo de inclusão é de fundamental importância, sendo necessário que o professor se perceba como um agente facilitador dos processos de aprendizagem (MANTOAN, 2006). 0 professor precisa considerar que, além do limite aparente, há possibilidades de aprendizagens e desenvolvimento, o que dependerá em boa parte da sua atuação.

0 processo inclusivo trouxe novos desafios e gerou muitas dúvidas e questionamentos. Nesse sentido, podemos afirmar que a educação inclusiva de qualidade pode consolidar um caminho de construções pedagógicas mais atrativas para todos.

\section{DIFICULDADES ENCONTRADAS PELOS PROFESSORES FACE AO PROCESSO DE INCLUSÃO DE ALUNOS COM DEFICIÊNCIA}

Ao analisar as respostas sobre as dificuldades encontradas pelos professores entrevistados para efetivar a educação inclusiva, organizei-as em: (a) Falta de preparo e de orientações sobre a deficiência específica de cada aluno incluso; (b) Necessidade da presença de um professor auxiliar na sala de aula; (c) Carência de apoio da supervisão escolar na prática inclusiva; (d) Escassez de materiais pedagógicos específicos para alunos inclusos.

\section{Falta de preparo e de orientações sobre a deficiência específica de cada aluno incluso}

Dois professores, dos cinco entrevistados, apontaram como dificuldade para a prática inclusiva a falta de orientação sobre a deficiência específica do aluno incluso, pela supervisão e coordenação escolar.

A partir da vivência como professora na rede regular de ensino pública e privada, constato que é muito comum na rotina escolar, os docentes receberem alunos inclusos, inseridos na classe regular, sem receberem orientações sobre a especificidade de sua deficiência, bem como, informações do histórico escolar e clínico do aluno.

A educação inclusiva implica um ensino adaptado às diferenças e às necessidades individuais, os educadores precisam estar habilitados para atuar de forma competente junto aos alunos inseridos e aos demais integrantes da classe, nos vários níveis de ensino. A falta de preparo e informação impede o professor de desenvolver uma prática pedagógica sensível às necessidades do aluno com deficiência incluído.

Nesta perspectiva, verifica-se que a inclusão em classes regulares, ainda necessita que profundas modificações sejam realizadas a fim de melhorar a qualidade da educação inclusiva.

\section{A necessidade da presença de um professor auxiliar na sala de aula}

Dois docentes entrevistados, quando perguntados sobre as dificuldades encontradas na prática inclusiva, afirmaram que acham necessária a presença de um profissional auxiliar na sala de aula, para que todos os alunos da turma sejam efetivamente atendidos.

A Resolução n.02/2001, do Conselho Nacional de Educação, trouxe um dos mais significativos progressos em relação ao processo de inclusão, onde aspectos importantes sobre as adaptações necessárias para o efetivo funcionamento do processo inclusivo foram normatizados. Especificamente, a partir desse documento, foram tratados determinados aspectos práticos, tais como: o ser- 
viço de apoio especializado, a organização da escola para o recebimento dos alunos, a adaptação curricular e a capacitação dos professores do ensino regular para a inclusão desses alunos nas classes regulares.

Neste contexto, o suporte dado ao aluno incluso através do profissional de apoio, refere-se ao desenvolvimento de uma ação colaborativa na sala de aula, envolvendo tanto o profissional auxiliar, quanto o aluno e o professor regente.

Em análise a legislação brasileira vigente, compreende-se que a presença de um profissional auxiliar na sala de aula, não é apenas uma reivindicação aleatória dos docentes entrevistados, trata-se de uma real dificuldade deparada na prática escolar pelos professores.

Sendo assim, temos claro que o professor de apoio é um profissional que acompanha o aluno, contribuindo na compreensão de suas características e eliminando barreiras que o impedem de se inserir na vida escolar. Assim, ele complementa o trabalho do educador regente da turma.

\section{Carência de apoio da supervisão escolar na prática inclusiva}

No depoimento do professor 2, em resposta a pergunta sobre as dificuldades encontradas no contexto inclusivo, foi ressaltada a importância do apoio da supervisão escolar na prática inclusiva.

Conforme o MEC (BRASIL, 2006), no documento Saberes e Práticas da Inclusão, Recomendações para a construção de escolas inclusivas, assinala que são necessários alguns apontamentos para o desempenho eficiente do Supervisor junto ao professor, na busca de uma promoção educacional formadora para os alunos com deficiência:

Desse modo, percebe-se que a atuação da supervisão escolar e de toda equipe pedagógica é imprescindível no processo da educação inclusiva, sendo necessário o estímulo para formação continuada do professor, como adaptação dos currículos, análises, orientações e informações, colaborando assim para aprendizagem dos educandos.

O supervisor tem por função harmonizar os saberes dos professores com a proposta de trabalho da escola e proporcionar elementos para que essa articulação aconteça efetivamente.

\section{Escassez de materiais pedagógicos específicos para alunos inclusos}

Foi constatado em três professores a preocupação com a falta de materiais pedagógicos específicos para trabalhar com a necessidade do aluno incluso.

Nessa perspectiva, para servir de sustentáculo ao atendimento escolar dos alunos com deficiência foi instituído o Atendimento Educacional Especializado (AEE), a partir do Decreto $\mathrm{n}$ - 6.571, de 17 de setembro de 2008 (BRASIL, 2008), que destaca, dentre outros objetivos, a elaboração e utilização de recursos que respondam aos ajustes necessários para a efetiva aprendizagem dos alunos inclusos.

Nesse propósito, o AEE é um serviço da Educação Especial que identifica, elabora e organiza recursos pedagógicos e de acessibilidade que eliminem barreiras para a plena participação dos alunos, considerando suas necessidades específicas. O AEE deve ser articulado com a proposta da escola regular, embora suas atividades se diferenciem das realizadas em salas de aula de ensino comum.

Segundo o MEC (BRASIL, 2009), o atendimento deve ser realizado no período inverso ao da classe frequentada pelo aluno e, preferencialmente, na própria escola. Nas escolas de ensino regular, o AEE deve acontecer em salas de recursos multifuncionais que é um espaço organizado com materiais didáticos, pedagógicos, equipamentos e profissionais com formação para o atendimento às necessidades educacionais especiais, projetadas para oferecer suporte necessário a estes alunos, favorecendo seu acesso ao conhecimento.

Desse modo, os professores das salas de AEE devem atuar de forma conjunta com o professor da classe comum para o planejamento de atividades pedagógicas que favoreçam o acesso do aluno ao currículo e a sua interação no grupo, entre outras ações que promovam a educação inclusiva.

Portanto, é indispensável que o docente tenha claro a necessidade de seu aluno e assim possa pla- 
nejar estratégias de ensino, bem como definir os materiais específicos que facilitarão a aprendizagem do aluno.

Nesse sentido, esses recursos devem ser utilizados no contexto educacional de forma a beneficiar a aprendizagem dos alunos inclusos.

Conforme os professores entrevistados, neste estudo, há uma enorme distância entre a proposta de inclusão educacional garantida pela legislação e a realidade no contexto escolar, constatando que a educação inclusiva tem um longo caminho a seguir para que a teoria e a prática engajem-se efetivamente.

\section{PRÁTICAS INCLUSIVAS DESENVOLVIDAS PELOS DOCENTES}

Ao examinar as respostas à pergunta sobre as práticas inclusivas desenvolvidas em aula pelos professores para efetivar a inclusão, organizei-as em três níveis: (a) prática direcionada à deficiência do aluno; (b) adaptação do sistema avaliativo; (c) uso do lúdico.

\section{Prática direcionada à deficiência específica do aluno}

Três professores participantes da pesquisa responderam que desenvolvem suas práticas voltadas para a deficiência específica do aluno.

A pesquisa realizada proporcionou aos professores uma reflexão sobre suas práticas inclusivas, oportunamente refletiram sobre seus planejamentos e práticas no processo inclusivo.

A formação continuada do professor é primordial, contudo, na medida em que se aproximam formação e vivência com os saberes que os educadores desenvolvem, acredito que está se caminhando rumo à inclusão efetiva.

\section{Adaptação do sistema avaliativo}

Dos cinco professores entrevistados, dois consideraram importante a adaptação específica avaliativa para cada aluno e sua respectiva deficiência.
Conforme Hoffman (2009) a avaliação, enquanto mediação significa encontro, abertura ao diálogo, interação, uma trajetória de conhecimento percorrida num mesmo tempo e cenário por alunos e professores. 0 processo de uma avaliação mediadora tem na interação, condição básica para seu sucesso.

Para tanto é importante se apontar rumos, capazes de conquistar o aluno, e despertar sua curiosidade, capacidades estas, presentes no professor mediador.

Nesta perspectiva o tempo de aprendizagem de cada estudante, deve ser respeitado em sua individualidade. 0 ponto de chegada atuaria apenas como pontos provisórios pelos quais passaria a aprendizagem. 0 educador necessita favorecer a evolução dos alunos e ao mesmo tempo, respeitar a individualidade de seus educandos no processo educacional, compreendendo a heterogeneidade do grupo.

A avaliação é uma prática intrínseca na educação escolar, faz parte do cotidiano, portanto, se faz necessário que os professores atuantes na rede regular, no contexto da educação inclusiva, adaptem seus instrumentos avaliativos de modo que contemple a todos os alunos pertencentes ao grupo.

Sendo assim, a avaliação deve oportunizar uma reflexão sobre as práticas pedagógicas, precisa ser utilizada de maneira a estar apropriada pelo processo, como algo integrado, do qual se sabe o verdadeiro propósito, deve ser valorizada como prática investigativa que dá suporte ao processo de aprendizagem de cada aluno.

\section{Uso do lúdico}

O uso do lúdico como estratégia de inclusão foi tratado pelo professor 5, revelando que desenvolve suas práticas priorizando os valores e as atitudes dos alunos:

As relações sociais e afetivas ajudam na construção da identidade, personalidade e cidadania, as atividades lúdicas podem criar um ambiente alegre e prazeroso, facilitando de forma agradável e criativa a aprendizagem, além de promover a inclusão. Guidetti e Moreira (2005) defendem que o 
uso do lúdico no ambiente escolar tem papel facilitador da aprendizagem:

[...] o lúdico tem o poder de incentivar tanto o progresso da personalidade integral quanto de cada uma das funções psicológicas, intelectuais e morais do educando. No mundo escolar tudo é novo e desafiador. Nesse ambiente totalmente desconhecido, o lúdico exerce o papel de mediador e facilitador da aprendizagem. (GUIDETTI; MOREIRA, 2005, p. 221).

Nesse sentido, é através do brincar que as crianças aprendem a conviver socialmente, a vivenciar limites, a criar laços sociais e ainda cumprir regras e normas. A atividade lúdica no ambiente escolar transforma-se em motivação para os alunos com deficiência, possibilitando a aprendizagem de forma prazerosa e divertida.

0 aluno com deficiência, integrado na rede regular de ensino, aprende através de diferentes linguagens, o papel fundamental do professor é definir o tipo de linguagem adequada que levará a criança a construir seu conhecimento.

Desse modo, o jogo, assim como o brinquedo e a brincadeira, precisa ser explorado de diversas formas, em várias ocasiões, de acordo com a realidade percebida. Isto significa que um jogo pode ter suas regras modificadas quando necessário, adequando-as a cada necessidade educativa especial, para evitar constrangimento às crianças que, por exemplo, tivessem uma limitação que as impedissem de jogar.

Cabe ao professor proporcionar oportunidades para que o jogo, o brinquedo e o brincar aconteçam de um modo educativo, em espaço físico agradável e materiais pedagógicos apropriados que possibilitem convívios enriquecedores e prazerosos. Nessa perspectiva, o brincar se torna um importante recurso a ser utilizado pedagogicamente nas escolas que tem as portas abertas para a inclusão, pois a ludicidade é importante e essencial para o desenvolvimento do aluno com deficiência, assim como também das demais crianças.

\section{CONTRIBUIÇÃO DOCENTE PARA A PRÁTICA DA INCLUSÃO}

Ao analisar as respostas sobre a contribuição dos professores para a prática da inclusão, organizei-as em três faixas: a) tratamento igualitário e desafiador; b) respeito à individualidade; c) busca de informação. Assim, o conjunto das respostas permitiu conhecer a realidade sobre a inclusão escolar no contexto pesquisado.

\section{Tratamento igualitário e desafiador}

0 primeiro entendimento refere-se ao tratamento dado pelo professor ao aluno incluso. Dois professores em seus depoimentos classificaram o tratamento igualitário e desafiador como prioridade em relação à inclusão.

Partindo do princípio de que "Todos são iguais perante a lei", garantido na Constituição Federal (1988), no Artigo 5o, constato que existe um embate no ambiente escolar, entre a lei e a aplicação, onde tem como desafio oferecer uma educação e aprendizagem de forma igualitária para todos os alunos.

Conforme previsto na constituição Federal (1988), o direito à educação para todos e de acesso universal, sob o lema de igualdade, não significa que a sua aplicação ocorra em pleno êxito no processo educacional, existem barreiras a serem vencidas; é preciso eliminar os privilégios através de atitudes pedagógicas capazes de visar à inclusão.

Sendo assim, o docente precisa reconhecer e valorizar as potencialidades dos alunos com deficiência, fazendo predominar as qualidades e não as dificuldades que enfrentam. $\mathrm{O}$ olhar do professor deve buscar a compreensão da diversidade existente na sala de aula, visando e oportunizando a aprendizagem de seus alunos e respeitando suas necessidades individuais.

\section{Respeito à individualidade}

Refere-se ao respeito à individualidade do aluno incluso, o segundo entendimento sobre a contribuição dos docentes entrevistados para a inclusão. 
0 professor 5 afirma que a aprendizagem deve ser contemplada dentro do tempo e individualidade de cada aluno:

Cabe ao professor buscar métodos para identificar as individualidades dos alunos, criar situações favoráveis à aprendizagem, tendo a concepção de que cada um aprende em seu ritmo. Há uma variedade de costumes e culturas dentro de uma sala de aula, portanto os alunos não possuem a mesma bagagem, os mesmos interesses e as mesmas maneiras de aprender. Compete ao professor diversificar as situações de aprendizagem, adequando as características próprias dos alunos, buscando caminhos educativos, valorizando e respeitando a diferenças individuais.

Nesse contexto, deve ser oportunizada ao aluno a demonstração de suas potencialidades e a valorização de seus muitos saberes, a escola necessita olhar para todos e para cada um.

\section{Busca de informação}

No que se refere ao terceiro entendimento sobre a contribuição dos docentes para a inclusão, dois professores afirmaram que buscaram informações sobre a deficiência do aluno incluso, para melhor desempenharem as suas aulas:

Na perspectiva da educação inclusiva, conforme a legislação, entendo que não cabe ao aluno se adaptar à escola tal como foi construída; mas a escola é que deve se reconstruir, adaptando espaços e recursos, para atender a toda a sua comunidade, da qual fazem parte pessoas com e sem deficiência.

Nesse contexto, é necessário que o professor veja cada aluno como um sujeito singular que tem uma história própria, que traz consigo conhecimentos anteriores à vida escolar, e que se constrói através das relações sociais existentes.

Para tanto, é preciso que o professor da sala regular tenha conhecimento sobre a deficiência do aluno incluso, identifique suas características e limitações através de acessos a laudos dos profissionais da saúde responsáveis pelo caso, além de entrevistas com os familiares da criança.

É importante que cada criança seja mediada com recursos que promovam a aprendizagem, desenvolvendo-se plenamente, já que todas são capazes de superar-se, desde que sejam ofertadas as condições necessárias.

Diante dos resultados deste estudo buscou-se elaborar uma proposta alternativa, a criação de um Guia de Boas Práticas.

Acredito que as boas práticas construídas durante as vivências em sala de aula, devem ser compartilhadas.

\section{Guia de boas práticas}

Segundo MEC (BRASIL, 2008) a definição de uma "boa experiência" consiste em toda atuação que se oriente a partir do compromisso dos professores, dos alunos e das famílias, em promover o acesso, a participação e a aprendizagem de todos os alunos.

Nessa perspectiva, acho oportuno conhecer novas experiências e saberes advindos do nosso cotidiano escolar, com o intuito de colaborar com os professores para enfrentarem as dificuldades encontradas no decorrer do exercício docente inclusivo.

Conforme o guia para a reflexão e avaliação de experiências educacionais inclusivas, elaborado pelo MEC (2008):

Uma experiência educacional inclusiva deve ser entendida como uma atuação "situada", que ganha sentido e é viável a partir de uma realidade concreta, dos condicionantes estruturais que a tornam única. Não há boas experiências ideais. Elas são dependentes invariavelmente do contexto onde se desenvolvem. (BRASIL, 2008, p.25).

O professor da área das Ciências Humanas precisa estar disposto a elaborar efetivamente as suas aulas inclusivas, oportunizando e mediando a aprendizagem de todos os alunos componentes da turma.

O Guia que apresento, como contribuição da pesquisa, está estruturado de modo a contemplar:

I - Formação inicial na graduação acadêmica

II - Realidade da inclusão escolar

III - Dificuldades no trabalho

IV - Práticas inclusivas 
1. Formação continuada

2. Tratamento igualitário e desafiador

3. Respeito à individualidade

4. Práticas direcionadas à deficiência específica

5. Uso do lúdico

6. Adaptação do sistema avaliativo

Tendo em vista a realidade sobre a formação acadêmica dos professores atuantes na rede regular de ensino, onde boa parte deles não foram preparados para atender alunos com deficiência inseridos na classe comum, cabe aos docentes, amparados pela coordenação escolar, buscar meios para desenvolver as aulas inclusivas, considerando o importante compromisso assumido com a educação.

0 professor, na educação inclusiva, precisa ser preparado para lidar com as diferenças, com a singularidade e a diversidade de todas as crianças:

Cabe a ele, a partir de observações criteriosas, ajustar suas intervenções pedagógicas ao processo de aprendizagem dos diferentes alunos, de modo que lhes possibilite um ganho significativo do ponto de vista educacional, afetivo e sociocultural (PRADO; FREIRE, 2001, p.5).

Para efetivação do processo de inclusão educacional, torna-se necessário o envolvimento de todos os membros da equipe escolar no planejamento de ações e programas voltados à temática. Docentes, diretores e funcionários apresentam papéis específicos, mas precisam agir coletivamente para que a inclusão escolar seja efetivada nas escolas.

Os professores da área das Ciências Humanas precisam priorizar os objetivos dos Parâmetros Curriculares Nacionais do Ensino Fundamental, levando em consideração a cidadania, objeto relevante desta área, garantindo ao aluno incluso, direitos civis e sociais.

Destaco aqui o seguinte objetivo:

Compreender a cidadania como participação social e política, assim como, exercício de direitos e deveres políticos, civis e sociais, adotando no dia-a-dia, atitudes de solidariedade, cooperação e repúdio às injustiças, respeitando o outro e exigindo para si o mesmo respeito. (BRASIL, 2000, p. irregular).

As práticas diárias devem ser refletidas pelos docentes constantemente, é preciso dar sentido ao ato de educar, seja para alunos ditos "normais" ou para alunos inclusos, se faz necessário acompanhar as mudanças e abraçar a diversidade contemporânea.

Professores, frente à realidade da inclusão escolar, têm se declarado desamparados quanto às informações relacionadas aos alunos inclusos, avaliam que falta suporte da coordenação pedagógica, constatando que ainda não há uma organização quanto à inclusão de alunos nas classes comuns.

Quando se pensa em acessibilidade na escola, os aspectos arquitetônicos são os primeiros a serem lembrados. No entanto, a condição que garante $o$ acesso sem barreiras a ambientes, materiais, serviços e informações vai muito além do espaço arquitetônico.

O MEC (BRASIL, 2008), conforme Decreto $n^{\circ}$ 6.571, de 17 de setembro do referido ano, preconiza que o atendimento educacional especializado deve ser organizado em salas de recursos multifuncionais ou centros de atendimento educacional especializado com recursos pedagógicos e de acessibilidade que eliminem as barreiras para a participação e aprendizagem, no ensino regular, considerando as necessidades específicas dos alunos.

Na perspectiva da educação inclusiva, o foco não é a deficiência do aluno e sim os espaços, os ambientes, os recursos que devem ser acessíveis e responder a especificidade de cada aluno.

Os materiais disponíveis na escola continuam sendo os mesmos que dispunham antes da inclusão, os prédios foram construídos sem atender as necessidades especiais, os professores foram formados para atender a classes homogêneas. Enquanto as políticas públicas criam leis para garantir o acesso do aluno com deficiência na escola regular, ainda há a falta de materiais pedagógicos para trabalhar com a inclusão.

Outro ponto mencionado pelos professores entrevistados é o horário de atendimento do aluno 
incluso na sala de recursos concomitante com o horário de aula na sala regular.

Na prática cotidiana se encontra a origem dos saberes, no entanto, esses saberes não podem ficar restritos apenas às certezas que o docente acumula de forma individual em sua carreira, é preciso serem compartilhados de forma a serem confrontados com o saber produzido pela experiência coletiva.

Atualmente, os profissionais da educação, diante da tarefa complexa que é educar no contexto da educação inclusiva, veem-se diante da necessidade de aprimorar suas práticas para responder às exigências que a proposta inclusiva estabelece. Nessa perspectiva, faz-se necessário considerar a reflexão sobre a prática como uma fonte de conhecimentos e alicerce para a construção de novos saberes.

\section{CONSIDERAÇÕES FINAIS}

0 presente estudo trabalhou com experiências vivenciadas por professores do ensino fundamental na rede regular de ensino, na área das Ciências Humanas, no contexto da inclusão escolar. Interessou-me problematizar acerca das estratégias e das práticas desenvolvidas atualmente por docentes que tiveram sua formação profissional, na cidade de Uruguaiana/RS, no período de 1988 a 2004, certificando-me de que a grade curricular do curso superior na área das Ciências Humanas não possuía disciplinas que contemplassem a educação inclusiva.

Nessa perspectiva, foi estudado como os professores entrevistados manifestam-se sobre suas práticas, e quais são suas práticas inclusivas usuais direcionadas para alunos com deficiência. A partir dos resultados desta pesquisa, propus como contribuição para o trabalho docente um guia de boas práticas.

Os depoimentos dos professores acerca das suas práticas inclusivas na sala de aula regular com alunos com deficiências apontam que a raiz das dificuldades enfrentadas se encontra na formação na graduação, onde apesar da existência de exigências legais quanto à oferta de disciplinas que tratasse da temática inclusão nos currículos dos cursos universitários, todos os entrevistados afirmaram que não foram contemplados, portanto sentiam-se inicialmente inseguros para atuar na realidade inclusiva. Esses relatos mostram que a formação inicial e continuada do professor é fundamental para a eficácia da educação inclusiva.

Nesse sentido, este estudo permitiu a constatação no que se refere à educação inclusiva, que muitas leis ainda não saíram da teoria, há uma enorme distância entre a proposta de inclusão educacional garantida pela legislação e a realidade no contexto escolar, constatando que a inclusão tem um longo caminho a seguir para que a teoria e a prática engajem-se efetivamente.

A partir da assimilação dos fatos, os entrevistados relataram que foram se adequando à realidade da inclusão na sala de aula e, consequentemente, aprendendo com a situação, buscaram por si próprios o aperfeiçoamento e qualificação para atender a todos os alunos.

Compreendi, a partir do estudo, que os docentes tiveram um novo olhar para os alunos inclusos, realizando as alterações necessárias para o acolhimento das crianças, demonstrando que, naquela situação desafiadora, necessitavam desempenhar a prática pedagógica inclusiva dentro de uma educação de qualidade.

Assim, fica claro que o professor desempenha função mediadora no processo ensino aprendizagem. Para tanto, precisa buscar formas de proporcionar interações sociais, atendendo às necessidades físicas e abrangendo o desenvolvimento intelectual do aluno, tornando assim o processo inclusivo significativo.

Nesse contexto, deve ser oportunizada ao aluno a demonstração de suas potencialidades e a valorização de seus saberes, a escola necessita olhar para todos e para cada um.

Este estudo traz algumas sugestões de boas práticas inclusivas, cunhadas a partir dos relatos dos professores entrevistados sobre os seus saberes construídos, bem como de suas dificuldades enfrentadas no cotidiano.

Espero que esta pesquisa desperte o interesse em outros professores para continuação da discussão em torno da temática inclusiva, a fim de que sejam compartilhados novos saberes e práticas diárias objetivando a concretização da educação inclusiva. 


\section{REFERÊNCIAS}

ALONSO, Myrtes. A supervisão e o desenvolvimento profissional do professor. In: FERREIRA, NauraSyriaCarapeto (Org.). Supervisão educacional para uma escola de qualidade. 4 ed. São Paulo: Cortez, 2003.

BARDIN, Laurence. Análise de conteúdo. São Paulo: Edições 70, 2011.

BOGDAN, R.; BIKLEN, S. Características da investigação qualitativa. In: Investigação qualitativa em educação: uma introdução à teoria e aos métodos. Porto (Portugal): Porto Editora, 1994.p. 47- 51.

BRASIL. Comitê Nacional de Educação em Direitos Humanos. Plano Nacional de Educação em Direitos Humanos. Brasília: Secretaria Especial dos Direitos Humanos, Ministério da Educação, Ministério da Justiça, UNESCO, 2006.Disponível em http://portal.mec.gov.br/seesp/arquivos/pdf/serie4.pdf>. Acesso em:23 ago.2014.

BRASIL. Constituição da República Federativa do Brasil de 1988. Disponível em: http://portal.mec.gov.br/cne/arquivos/. Acesso em:23ago. 2014.

BRASIL. Convenção sobre os Direitos das Pessoas com Deficiência.2009. Disponível em http://portal.mec.gov.br. Aces-

BRASIL. Decreto n. 6571, de 17 de setembro de 2008.Trata do atendimento educacional especializado.Disponível em: < http://portal.mec.gov.br/seesp/arquivos/pdf/serie4.pdf> Acesso em:23 ago.2016.

BRASIL. Diretrizes Nacionais para a Educação especial na Educação Básica.

Diário Oficial da União, Brasília, DF. 4 set. 2001. Disponível em: http://portal.mec.gov.br/cne/arquivos/. Acesso em: 23ago.2014.

BRASIL. Estatuto da Criança e do Adolescente no Brasil. Lei no 8.069, de 13 de julho de 1990. Disponível em http://portal. mec.gov.br/cne/arquivos/. Acesso em:23ago. 2014.

BRASIL. IBGE - Instituto Brasileiro de Geografia e estatística. Disponível: http://www.ibge.gov.br. Acesso em: 10 abr. 2017.

BRASIL. Estatuto da Pessoa com Deficiência. Lei no. 13.146 de 06 de julho de 2015. Institui a Lei Brasileira de Inclusão da Pessoa com Deficiência. Disponível em <http://portal.mec.gov. br/seesp/arquivos/pdf/serie4.pdf>. Acesso em:14ago. 2015. BRASIL. Ministério da Educação. Lei de Diretrizes e Bases da Educação Nacional n. 9.394/1996. Brasília. 1996. Disponível em: http://portal.mec.gov.br/cne/arquivos/. Acesso em:23 ago.2014.

BRASIL. Ministério da Educação. Política Nacional de Educação Especial na perspectiva da Inclusão. 2008.Disponível em http://portal.mec.gov.br. Acesso em: 10 out. 2014.

BRASIL. Ministério da Educação. Portaria n.o 1793/94. Brasília, 1994.

BRASIL. Ministério da Educação. Saberes e práticas da Inclusão. 2006. Disponível em http://portal.mec.gov.br. Acesso em: 15 abr. 2017.

BRASIL: Ministério da Educação. Secretaria de Educação Especial. Sala de Recursos

Multifuncionais: espaços para o Atendimento Educacional Especializado. Brasília: MEC/SEESP, 2006.

BRASIL. Resolução CNE/CP n. 2, de 11 de Setembro de 2001 Disponível em: <http://portal.mec.gov.br/cne/arquivos/. Acesso em:23 ago. 2014.

CARVALHO, RositaEdler. Educação Inclusiva: com os pingos nos “is". Porto Alegre: Mediação. 2006.

DANESI, Marlene Canarim; TIMM, Edgar Zanini. Caminhos da educação inclusiva. Porto Alegre, RS: Universitária Metodista IPA, EDIPUCRS, 2013.

FREIRE, Paulo. Pedagogia da autonomia: saberes necessários à prática educativa. 23.ed.São Paulo: Paz e Terra, 1996.

GUIDETTI, Josieli; MOREIRA, Ariane. Lúdico: alfabetizar brincando. In: ANTUNES, Helenise S. Trajetória Docente: o encontro da teoria com a prática. Santa Maria: Universidade Federal de Santa Maria, Departamento de Metodologia do Ensino, 2006.

HOFFMANN, Jussara. Avaliação mediadora: uma prática em construção da pré-escola a universidade. Porto Alegre: Mediação, 2009.

MANTOAN, Maria Tereza. Atendimento educacional especializado. São Paulo: MEC/SEESP, 2006.

MANZINI José Eduardo. Entrevista semiestruturada: análise de objetivos e de roteiros. São Marília: Depto de Educação Especial, Programa de Pós-Graduação em Educação, Unesp, 2004.

MINAYO, Maria Cecília de Souza. Pesquisa Social: teoria, método e criatividade.24. ed. Petrópolis, RJ: Vozes, 2010.

PRADO, M.E.B.B.; FREIRE, F. M. P. A formação em serviço visando a reconstrução da prática educacional. In: FREIRE, F. M. P.; VALENTE, A.(Orgs). Aprendendo para a Vida: os Computadores na Sala de Aula. São Paulo: Cortez, 2001. 
SANTOS, Fernanda Marsaro dos. Análise de conteúdo: a visão de Laurence Bardin. Resenha de: [BARDIN, L. Análise de conteúdo. São Paulo: Edições 70, 2011, 229p.] Revista Eletrônica de Educação. São Carlos, SP: UFS Car, v. 6, n. 1, p.383-387, mai. 2012. Disponível em: http://www.reveduc.ufscar.br. Acesso em 07 fev.2015.
SANTOS, Santa. M.P. A ludicidade como ciência. Petrópolis, Rio de janeiro: Vozes, 2003.

VYGOTSKY, LevSemenovich. A formação social da mente. São Paulo: Martins Fontes, 1998. 